\title{
REVIEW \\ Non-invasive electrocardiographic assessments of cardiac autonomic modulation in individuals with spinal cord injury
}

\author{
H Sharif ${ }^{1,2}$, PJ Millar ${ }^{3}$, AV Incognito ${ }^{3}$ and DS Ditor ${ }^{1,2}$
}

\begin{abstract}
Study design: Review.
Objectives: The purpose of this review is to discuss the utility of linear and non-linear heart rate variability (HRV) as well as the QT-variability index (QTVI) as indices of cardiac autonomic control in individuals with spinal cord injury (SCI).

Setting: Brock University, Department of Kinesiology, St Catharines, Ontario, Canada. Brock-Niagara Centre for Health and Well-being, St Catharines, Ontario, Canada.

Methods: Literature review.

Conclusion: Non-invasive markers determined from the electrocardiogram, such as linear and non-linear HRV, and, more recently, the QTVI have all shown some promise as indices of cardiac autonomic regulation in the SCI population. However, there are inconsistencies in the literature that call to question their true validity in this regard. Studies using pharmacological blockade, sympathetic manoeuvres and exercise suggest that both linear and non-linear HRV reflect cardiac parasympathetic activity, whereas their ability to quantify cardiac sympathetic outflow remains uncertain. The QTVI, although a novel method, correlates with both limbs of the autonomic nervous system and therefore may hold value as a measure of both cardiac sympathetic and parasympathetic activity in individuals with $\mathrm{SCl}$; however, more research is required to confirm its utility.
\end{abstract}

Spinal Cord (2016) 54, 166-171; doi:10.1038/sc.2015.207; published online 24 November 2015

\section{INTRODUCTION}

Developing a method that quantifies cardiac autonomic activity in individuals with spinal cord injury (SCI) has been a topic of significant interest over the past two decades. Although there has been many advances, there remains a lack of consensus on a single, non-invasive measure of cardiac autonomic function in this population. SCI presents a unique model of autonomic dysfunction that is associated with a variety of impairments, including broncho-pulmonary dysfunction $^{1}$ reduced bladder control, ${ }^{2}$ sexual dysfunction ${ }^{3,4}$ and gastrointestinal issues. ${ }^{5}$ In addition, autonomic dysfunction contributes both directly and indirectly to the increased risk for cardiovascular morbidity and mortality in the SCI population. ${ }^{6,7}$ In general, an injury above the 5th thoracic level results in reduced cardiac autonomic regulation due to reduced supraspinal control over preganglionic sympathetic neurons. ${ }^{8}$ In contrast, cardiac parasympathetic outflow is preserved as the vagus nerve is not interrupted by the SCI. Therefore, it is important to develop valid measures of cardiac autonomic activity to gauge the cardiac sympathetic function and to assess cardiac autonomic imbalances as they may have detrimental consequences. ${ }^{6,9,10}$

Beat-to-beat control of $\mathrm{HR}$ is tightly regulated by autonomic activity; $^{11,12}$ thus, the electrocardiogram may represent a noninvasive method to assess the cardiac autonomic function. The purpose of this review is, therefore, to discuss three electrocardiogram-based methods currently used to quantifying the cardiac autonomic function in individuals with SCI: heart rate variability (HRV), non-linear heart rate dynamics and the QT-variability index (QTVI). Although these indices are used in clinical and investigative settings, the physiological correlates of some still remain equivocal, and the use of some may provide false results. ${ }^{13}$ As such, this review will discuss the physiological basis of these measures, their clinical applicability, their use in the SCI population and recommendations for their utility.

\section{VALIDITY OF CARDIAC AUTONOMIC MEASURES \\ Heart rate variability}

Heart rate demonstrates normally occurring oscillations in beat-tobeat variability that reflect modulation of sympathetic and parasympathetic inputs. ${ }^{14}$ Time- and frequency-domain techniques have been developed to utilise such HRV as an indirect marker of cardiac autonomic modulation. Time-domain HRV can be mathematically calculated through methods such as standard deviation of all RR intervals (SDNN), standard deviation of the averages of RR intervals from a 5-min segment and root mean square of differences between RR intervals. ${ }^{15}$ For analysis of frequency-domain HRV, successive RR intervals from an electrocardiogram are plotted against time to create a tachogram, which is then evaluated through spectral density analysis. In healthy humans, resting successive RR intervals oscillate around 2 main frequencies: low frequency (LF; $0.04-0.15 \mathrm{~Hz}$; centre frequency: $0.1 \mathrm{~Hz}$ ) and high frequency (HF; $0.15-0.40 \mathrm{~Hz}$; centre frequency: $0.25 \mathrm{~Hz}){ }^{16}$

${ }^{1}$ Department of Kinesiology, Brock University, St Catharines, Ontario, Canada; ${ }^{2}$ Brock-Niagara Centre for Health and Well-being, St Catharines, Ontario, Canada and ${ }^{3}$ Department of Human Health and Nutritional Sciences, University of Guelph, Guelph, Ontario, Canada

Correspondence: Dr DS Ditor, Department of Kinesiology, Brock University, 500 Glenridge Ave, St Catharines, Ontario, Canada L2S 3A1.

E-mail: dditor@brocku.ca

Received 19 June 2015; revised 9 October 2015; accepted 16 October 2015; published online 24 November 2015 
Although studies using stress manoeuvres suggest that HF power reflects cardiac parasympathetic outflow, whereas LF represents sympathetic activity, ${ }^{17}$ other research has questioned the validity of these measures. Early results from Pomeranz and colleagues showed that atropine, a cholinergic blocker that reduces cardiac parasympathetic activity, almost completely abolished HF power and significantly reduced LF power during supine resting conditions. ${ }^{18}$ Likewise, while standing, LF power was significantly reduced after infusion of propranolol, a $\beta$-blocker that reduces cardiac sympathetic activity; however, LF power was further attenuated after additional atropine administration. These findings suggest that LF power is influenced by both cardiac sympathetic and parasympathetic activity, whereas HF power reflects the latter. Thus, the LF:HF ratio has been used for the estimation of cardiac sympathovagal balance. ${ }^{19}$ However, a recent review provides substantial evidence negating the use of LF power and the LF:HF ratio for their purported purposes, ${ }^{13}$ and these limitations are discussed in more detail below.

\section{Non-linear heart rate dynamics}

Cardiac sympathetic and parasympathetic interactions on HR are complex and are not always reciprocal or linear..$^{20,21}$ This has stimulated interest in variability measures based on chaos theory and non-linear systems theory in the hopes of elucidating a marker that more accurately quantifies cardiac autonomic modulation and clinical risk. The non-linear measures most frequently used in physiological and clinical trials ${ }^{22}$ have been created to assess signal complexity or randomness (for example, approximate entropy, sample entropy), self-similarity (for example, detrended fluctuation analysis, power-law exponent) or fractal dimensions (for example, correlation dimension, Poincare plot). Evidence for weak relationships between linear and non-linear measures of HRV ${ }^{23-25}$ may suggest that nonlinear measures offer unique or complimentary information regarding the modulation of HR.

The current data on non-linear measures are limited and conflicting with regard to its reproducibility and physiological basis. The reproducibility of non-linear measures over time has been both confirmed ${ }^{26-29}$ and refuted, ${ }^{30}$ whereas the physiological background of non-linear HRV is also poorly understood due to conflicting results from studies employing autonomic blockade or stimuli. For example, measures of HR complexity while under vagal blockade have been shown to be unaffected, ${ }^{31,32}$ reduced $^{20}$ or almost completely abolished..$^{33-35}$ Further, HR complexity is reduced by standing ${ }^{36}$ and increased during low-intensity dynamic exercise ${ }^{25}$ but unaltered during sympathetic blockade, ${ }^{35}$ passive head-up tilt ${ }^{25}$ or autonomic stress. $^{35}$ Differences in circulating catecholamine concentrations evoked by each stimulus have been proposed to explain divergent complexity responses, ${ }^{25}$ but this concept requires further investigation. Examination of the short-term fractal scaling exponent $\left(\alpha_{1}\right)$ determined by detrended fluctuation analysis has also produced conflicting results. This measure, which quantifies the fractal-like correlation properties of the HR signal, has been shown to be reduced by norepinephrine infusion, ${ }^{37}$ cold face immersion ${ }^{38}$ or progressive dynamic exercise ${ }^{36}$ and increased during standing, ${ }^{36}$ low-intensity dynamic exercise, ${ }^{25}$ passive head-up tilt ${ }^{25}$ or cold hand immersion, ${ }^{38}$ and unaffected $^{35}$ or increased ${ }^{25,32}$ by atropine administration. Nonetheless, similar to linear HRV, the majority of non-linear measures of HR appear to be impacted more by cardiac vagal than sympathetic modulation.

\section{QT-variability index}

The QTVI is a measure of beat-by-beat repolarisation variability that was initially developed for the purposes of assessing repolarisation lability ${ }^{39}$ and as a prognostic tool for risk of ventricular arrhythmia in cardiac patients. ${ }^{40}$ However, because the QTVI takes the QT and RR intervals into account (both intervals being influenced by autonomic activity), ${ }^{11,18,41}$ this measure has been proposed to hold some efficacy in assessing cardiac autonomic activity.

The QTVI has been shown to increase during conditions that augment cardiac sympathetic activity such as standing and isoprotenerol infusion, ${ }^{42}$ autonomic stress ${ }^{43}$ and hypertension, ${ }^{44}$ as well as during situations that reduce vagal activity, such as cardiac autonomic neuropathy ${ }^{45}$ and aging. ${ }^{46}$ To date, the most compelling evidence for the physiological basis of the QTVI was an animal study by Piccirillo et al. $^{47}$ that demonstrated an inverse relationship between the QTVI and integrated vagal nerve activity during rest in dogs but a direct relationship between QTVI and integrated stellate ganglionic nerve activity during heart failure. Accordingly, such clinical and experimental studies suggest that the QTVI may reflect both cardiac sympathetic and parasympathetic activities, depending on the autonomic state of the individual.

\section{CLINICAL UTILITY OF CARDIAC AUTONOMIC MEASURES}

\section{Heart rate variability}

Several studies have demonstrated the prognostic value of HRV for identifying the risk of mortality in various cardiovascular populations. A reduction in time-domain HRV has been shown to be associated with an increased relative risk of all-cause mortality, ${ }^{48}$ cardiac mortality ${ }^{49}$ and sudden cardiac death ${ }^{7,50}$ in post-myocardial infarction patients. A reduction in HRV has also been shown in patients with hypertension ${ }^{51}$ congestive heart failure ${ }^{52}$ and diabetes. ${ }^{53}$ With regard to frequency-domain $\mathrm{HRV}$, both short-term ${ }^{54}$ and long-term ${ }^{55}$ recordings have shown to be useful for risk stratification and the prediction of sudden death in individuals with chronic heart failure. ${ }^{56-58}$ In addition, it has been reported that HRV has greater prognostic value than commonly used measures, such as left ventricular ejection fraction, wall motion abnormalities and exercise capacity. ${ }^{59}$ Still, there is no widely accepted value for any frequencydomain measures of HRV that is used as a threshold of cardiac risk.

\section{Non-linear heart rate dynamics}

Accumulating evidence demonstrates a prognostic role for non-linear measures of HRV in identifying individuals at risk of cardiovascular events or mortality. This work has focused primarily on fractal-like correlation or self-similarity measures of HR behaviour, such as power-law slope and $\alpha_{1}$. These measures have demonstrated the ability to predict mortality in patients following myocardial infarction, ${ }^{58}$ better than ${ }^{60,61}$ and independent of ${ }^{62}$ linear HRV. Further research has established a similar role for predicting vulnerability to ventricular tachycardia, ${ }^{63}$ ventricular fibrillation, ${ }^{64}$ arrhythmic and non-arrhythmic cardiac death, ${ }^{61}$ nonfatal coronary events ${ }^{65}$ and heart failure admissions ${ }^{66}$ in post-myocardial infarction patients. Premature mortality in other clinical populations is also associated with reduced measures of complexity. ${ }^{67,68}$ The utility of non-linear measures of HR dynamics is further emphasised by their ability to predict increased risk of cardiovascular causes of death better than traditional timeand frequency-domain indices in a random population of elderly individuals. ${ }^{69}$ 


\section{QT-variability index}

Several investigations have reported the ability of the QTVI to predict risk of sudden cardiac death in clinical populations. A higher QTVI value is suggestive of greater repolarisation variability, which is indicative of a less stable myocardium, and thus, a greater risk for arrhythmogenesis. Conversely, a lower value is indicative of a more stable myocardium. The QTVI has been reported to be elevated in several conditions, including dilated cardiomyopathy ${ }^{39}$ hypertension, ${ }^{44}$ heart failure, ${ }^{70}$ anxiety and depression. ${ }^{71}$ In addition, Atiga et al. ${ }^{40}$ reported that the QTVI was a sensitive predictor of future arrhythmia and a more accurate predictor of sudden cardiac death compared with spatial QT dispersion, HRV and ejection fraction in patients with heart disease. The prognostic value of QTVI for cardiac mortality has also been demonstrated in asymptomatic heart failure patients ${ }^{72}$ and in the general population. ${ }^{73}$ Moreover, the QTVI was shown to be a useful tool in stratifying severities of cardiac autonomic neuropathy diabetic patients. $^{45}$

\section{EFFECT OF SCI ON INDICES OF THE CARDIAC AUTONOMIC FUNCTION}

\section{Heart rate variability}

HRV analysis has been used in the SCI population to estimate cardiac autonomic integrity and, to a lesser extent, cardiovascular risk. Although HRV has been shown to be reliable and reproducible in individuals with SCI, ${ }^{74}$ the physiological basis of this measure remains somewhat equivocal, especially pertaining to the interpretation of the LF component. For example, earlier work by Inoue et al. ${ }^{75}$ suggested that LF power corresponds to cardiac sympathetic outflow, as individuals with complete tetraplegia failed to show any sign of it. Contradicting work by Koh et al. ${ }^{76}$ demonstrated that LF power reflects cardiac vagal outflow, as atropine administration abolished LF power in individuals with SCI. Guzzetti and colleagues showed that half of their cohort with complete tetraplegia exhibited a detectable LF component, suggesting that, in some individuals, LF power corresponds to sympathetic spinal rhythmicity. ${ }^{77}$ Moreover, Inoue et al. ${ }^{78}$ reported that the physiological correlates of LF power in individuals with tetraplegia may be different from those in able-bodied individuals and that LF power in individuals with SCI is simply a reflection of reflex sympathetic outflow caused by stimuli from the periphery (bladder or bowel distension or spasms from the limbs). In conclusion, these conflicting results suggest that the LF power in individuals with SCI reflects cardiac sympathetic innervation, ${ }^{75}$ cardiac vagal innervation, ${ }^{76}$ spinal rhythmicity ${ }^{77}$ or reflexive sympathetic outflow. ${ }^{78}$

Without doubt it is difficult to discern the physiological correlates of the LF component of HRV in individuals with SCI. Some of the confusion in this area may be attributed to the early assumptions that individuals with complete sensorimotor injuries are also autonomically complete, which have since been shown as incorrect. ${ }^{79}$ In addition, the studies described above demonstrate a wide range of inter-participant variability that may obscure mean findings. Therefore, the physiological basis of LF power cannot be determined by these previous studies.

Notwithstanding the limitations of the LF:HF ratio as a measure of sympathovagal balance, ${ }^{13}$ the concomitant reduction in $\mathrm{HF}$ power alongside LF power following SCI has been suggested to be a result of the body's attempt to maintain cardiac sympathovagal modulation..$^{80,81}$ Other investigations have suggested that the reduced HF power may be due to altered cardiac cholinergic receptor response to vagal outflow. For example, Wecht et al. ${ }^{82}$ reported comparable degrees of HF withdrawal among individuals with tetraplegia, paraplegia and able-bodied controls in response to head-up tilt. However, the subsequent increase in HR was blunted in the group with tetraplegia, which may be due to altered sino-atrial node response to vagal withdrawal. Further, Wecht et al. ${ }^{83}$ examined cardio-autonomic response to the cold face test, a stimulus that increases vagal activity, in young able-bodied participants, older able-bodied participants and individuals with SCI. ${ }^{84}$ Individuals with SCI and older adults demonstrated a similar attenuation in HF response to the cold face test compared with young participants, suggesting accelerated cardiac vagal aging in young healthy individuals with SCI. Although both younger and older participants showed an expected bradycardia during the test, those with SCI presented a paradoxical increase in HR, which was attributed to either the SCI per se or the profound physical inactivity associated with SCI. ${ }^{83}$ Alternatively, this paradoxical increase in HR could also be attributed to a potential impairment in the accentuated antagonism response, ${ }^{85}$ in which there is a reduction in the normal parasympathetic dominance over the effects produced by the simultaneous increase in sympathetic outflow during the cold face test. ${ }^{86}$

These observations suggest that a possible alteration in sino-atrial nodal response to vagal activity could be accountable for the reduced HF power reported following SCI. However, another possible explanation for the reduced HF power following SCI is the profound physical inactivity associated with this population. This is evidenced by studies demonstrating increased HF power following a period of exercise $^{87}$ and better HF dynamics in physically fit SCI individuals compared with their sedentary counterparts. ${ }^{88,89}$ These reports strongly suggest that the previously observed reduction in $\mathrm{HF}$ power ${ }^{90,81}$ is not a compensatory mechanism to maintain sympathovagal balance but may be a reflection of the severe physical inactivity in this population..$^{91}$

One of the conditions for the validity of HRV as a measure of the cardiac autonomic function is that it should change significantly after administration of autonomic blockade. ${ }^{91}$ Results from our laboratory ${ }^{92}$ showed that, during cardiovascular stress, metoprolol administration resulted in variable amounts of reduction in the LF:HF ratio $(40-73 \%)$, whereas atropine completely abolished HF power during rest. These results confirm that, in individuals with SCI, the HF power corresponds to cardiac vagal outflow; however, because of the variable and incomplete reduction in the LF:HF ratio in response to metoprolol, its association with cardiac sympathetic regulation is unclear.

Taken together, two conclusions can be drawn from the aforementioned investigations. First, the HF component of HRV seems to be a valid measure of cardiac vagal activity in individuals with SCI. Second, it is still unclear what the LF component of HRV corresponds to in individuals with SCI due to conflicting results. ${ }^{75-78}$ Likewise, the most recent investigation regarding the physiological correlates of HRV after SCI showed that the LF:HF response to sympathetic blockade is considerably variable within individuals with incomplete SCI. ${ }^{92}$ This lack of consensus on the validity of the LF power in individuals with SCI makes it difficult to delineate what it truly represents, and using it in research or clinical investigations may lead to spurious conclusions.

\section{Non-linear heart rate dynamics}

A limited number of investigations have used non-linear HRV methods to investigate the effects of SCI on cardiac autonomic modulation. Millar et al. ${ }^{35}$ confirmed a similar role for cardiac vagal modulation in the genesis of HR complexity in individuals with incomplete tetraplegia and able-bodied controls. Measures of nonlinear heart rate dynamics were similar between individuals with SCI and able-bodied controls at baseline and in response to sympathetic blockade with metoprolol and vagal blockade with atropine. 
In response to a cardiovascular stress, baseline HR complexity was lower in those with SCI, but vagal blockade again reduced overall complexity in both groups and ameliorated these group baseline differences. These results suggest that HR complexity is similarly modulated primarily by cardiac parasympathetic activity in both SCI and $\mathrm{AB}$ populations. Non-linear measures of $\mathrm{HR}$ complexity also demonstrate excellent intra- and inter-visit reproducibility (greater than frequency parameters) in individuals with tetraplegia. ${ }^{29}$

Non-linear measures of HR dynamics have shown a unique ability to uncover novel information not obtained by traditional linear HRV methods. Merati et al. demonstrated that non-linear measures were sensitive to differences in the SCI lesion level, with complexity lower in individuals with SCI lesions between T5-L4 than able-bodied controls and measures of self-similarity higher in those with SCI (T5-L4 or C6-T4) than able-bodied controls. These differences were not detected using traditional time- or frequency-domain measures of HRV. ${ }^{93}$ More recently, Zamunér et al. reported that only non-linear measures of complexity were able to discriminate between those with paraplegia who are sedentary and those who are active or able-bodied controls. ${ }^{88}$

Two studies have employed non-linear measures of HR dynamics to examine the acute or chronic response to a stressor in individuals with SCI. Agiovlasitis et al. ${ }^{94}$ reported that collegiate athletes with paraplegia had lower HR complexity at baseline and in response to a 2-min bout of static handgrip than similarly active able-bodied controls, with no differences in HRV between groups. Millar et al. found alterations in non-linear measures of HR dynamics following 4 weeks of bodyweight supported treadmill training, but not head-up tilt training, in individuals with SCI, whereas HRV measures were unchanged with both interventions. ${ }^{95}$ Collectively, these results demonstrate that nonlinear measures of HR dynamics are sensitive to smaller changes in heart rate behaviour and/or detect unique information not quantified by linear methodologies. These methods may be useful in detecting dysfunction of the autonomic nervous system present in individuals with SCI. It also seems that non-linear measures of HR dynamics mainly reflect cardiac parasympathetic activity in individuals with SCI, as shown by studies employing autonomic blockade ${ }^{35}$ and exercise training. ${ }^{95}$ However, similar to linear HRV, the ability of non-linear measures to assess cardiac sympathetic activity in individuals with SCI has yet to be validated.

\section{QT-variability index}

Because of the QTVI being a relatively novel method for assessing the cardiac autonomic function, literature regarding its use after SCI is relatively scarce. In the first study to investigate the QTVI in individuals with SCI, La Fountaine et al. compared resting QTVI values between able-bodied controls and individuals with tetraplegia, high paraplegia and low paraplegia. Results showed that all SCI groups had significantly elevated QTVI values compared with the able-bodied group, whereas there were no difference between any of the SCI groups. In addition, QTVI showed a negative correlation with HF power in all SCI groups, whereas LF power was negatively correlated with the QTVI only in the groups with sympathetic dysfunction (tetraplegia and high paraplegia). ${ }^{96} \mathrm{~A}$ possible explanation for the comparable QTVI values among the SCI groups is that the SCI participants were not compared based on the amount of autonomic function. This was addressed by Ravensbergen et al., who showed that the elevated QTVI in individuals with SCI was related to both the level of injury and autonomic completeness, as those with injuries above T5 and/or autonomically complete injuries exhibit higher QTVI values compared with able-bodied controls. ${ }^{97}$
Although these cross-sectional studies ${ }^{96,97}$ provide evidence for elevated QTVI in individuals SCI, they do not specifically discern the physiological basis of the QTVI following SCI. Accordingly, a recent study conducted by our group ${ }^{43}$ investigated the contribution of cardiac autonomic activity to the QTVI in individuals with incomplete tetraplegia in response to cardiovascular stress and autonomic blockade. Results showed that, in both the able-bodied and SCI groups, the QTVI significantly increased during cardiovascular stress and subsequently decreased after Metoprolol infusion during the cardiovascular stress. Further, atropine significantly increased the QTVI during resting supine conditions. These results suggest that, in autonomically incomplete injuries, the QTVI may reflect cardiac sympathetic activity during times of sympathetic arousal and inversely reflects cardiac vagal activity during vagal dominance. Although it is clear that the QTVI reflects cardiac autonomic activity and may hold value as a valid index of cardiac autonomics in individuals with SCI, all of the knowledge obtained about this measure is from cross-sectional studies ${ }^{96,97}$ or experimental studies with small sample sizes. ${ }^{43}$ Therefore, further large-scale, longitudinal studies are warranted to confirm these results, as this method may hold clinical and physiological importance.

\section{CONCLUSION}

The physiological basis of these non-invasive measures must be well understood by investigators and clinicians who wish to employ them for assessing the cardiac autonomic function in individuals with SCI. Measures such as HF power, time-domain HRV, non-linear HRV (complexity) and QTVI may be used to assess the cardiac vagal function in SCI. In contrast, with the potential exception of the QTVI, the electrocardiogram-based measures discussed in this review are limited in their ability to assess the cardiac sympathetic function in individuals with SCI. Accordingly, researchers should refrain from using LF power and the LF:HF to gauge cardiac sympathetic activity in this population. Furthermore, the QTVI may hold promise as an index of both cardiac sympathetic and parasympathetic activity after $\mathrm{SCI}$, but further research is required to confirm the efficacy of this tool.

\section{CONFLICT OF INTEREST}

The authors declare no conflict of interest.

\section{ACKNOWLEDGEMENTS}

This work was funded by the Ontario Neurotrauma Foundation.

1 Brown R, DiMarco AF, Hoit JD, Garshick E. Respiratory dysfunction and management in spinal cord injury. Respir Care 2006; 51: 853-870.

2 De Groat WC. Mechanisms underlying the recovery of lower urinary tract function following spinal cord injury. Spinal Cord 1995; 33: 493-505.

3 Monga M, Bernie J, Rajasekaran M. Male infertility and erectile dysfunction in spinal cord injury: a review. Arch Phys Med Rehabil 1999; 80: 1331-1339.

4 Sipski ML, Alexander CJ. Sexual activities, response and satisfaction in women pre-and post-spinal cord injury. Arch Phys Med Rehabil 1993; 74: 1025-1025.

5 Lynch AC, Antony A, Dobbs BR, Frizelle FA. Bowel dysfunction following spinal cord injury. Spinal Cord 2001; 39: 193-203.

6 Collins HL, Rodenbaugh DW, Di Carlo SE. Spinal cord injury alters cardiac electrophysiology and increases the susceptibility to ventricular arrhythmias. Prog Brain Res 2006; 152: 275-288.

7 Myers J, Lee M, Kiratli WJ. Cardiovascular disease in spinal cord injury an overview of prevalence, risk, evaluation, and management. Am J Phys Med Rhabil 2007; 86: $142-152$.

8 Krassioukov AV, Bunge RP, Pucket WR, Bygrave MA. The changes in human spinal sympathetic preganglionic neurons after spinal cord injury. Spinal Cord 1999; 37: 6-13. 
9 Rodenbaugh DW, Collins HL, DiCardlo SE. Increased susceptibility to ventricular arrhythmias in hypertensive paraplegic rats. Clin Exp Hyperten 2003; 25: 349-358.

10 Forrest FP. Atrial fibrillation associated with autonomic dysreflexia in patients with tetraplegia. Arch Phys Med Rehabil 1991; 72: 592-594.

11 Magnano AR, Holleran S, Ramakrishnan R, Raffiel JA, Bloomfield DM. Autonomic nervous system influence on QT interval in normal subjects. J Am Coll Cardiol 2002; 39: 1820-1826.

12 Verrier RL, Antzelevitch C. Autonomic aspects of arrhythmogenesis: the enduring and the new. Curr Opin Cardiol 2004; 19: 2-11.

13 Billman GE. The LF/HF ratio does not accurately measure cardiac sympatho-vagal balance. Front Physiol 2013; 4: 26

14 Askelrod SD, Gordon FA, Ubel DC, Shannon AC, Berger, Cohen RJ. Power spectrum analysis of heart rate fluctuations: a quantitative probe of beat-to-beat cardiovascular control. Science 1981; 213: 220-222.

15 Cam AJ, Malik M, Bigger JT, Breithardt G, Cerutti S, Cohen RJ et al. Heart rate variability: standards of measurement, phsyological interpretation and clinical use. Circulation 1996; 93: 1043-1065.

16 Kammath MV, Fallen EL. Power spectral analysis of heart rate variability. A non-invasive signature of cardiac autonomic function. Crit Rev Biomed Eng 1993; 21 245-311.

17 Montano N, Gneechi T, Porta A, Lombardi F, Pagani M, Malliani A. Power spectrum analysis of heart rate variability to assess the changes in sympathovagal balance during graded orthostatic tilt. Circulation 1994; 90: 1826-1831.

18 Pomeranz B, Macaulay RJ, Caudill MA, Kutz I, Adam D, Gordon D et al. Assessment of autonomic function in humans by heart rate spectral analysis. Am J Physiol 1985; 248 H151-H153.

19 Malik M, Camm AJ. Heart Rate Variability. Futura Press: NY, USA, 1995

20 Hagerman I, Berglund M, Lorin M, Nowak J, Sylven C. Chaos-related deterministic regulation of heart rate variability in time- and frequency domains: Effects of autonomic blockade and exercise. Cardiovasc Res 1996; 31: 410-418.

21 Silke B, Riddell JG. Evaluation of the effect on heart rate variability of some agents acting at the b-adrenoceptor using nonlinear scatterplot and sequence methods. Cardiovasc Drugs Therap 1998; 12: 439-448.

22 Huikuri HV, Perkiömäki JS, Maestri R, Pinna GD. Clinical impact of evaluation of cardiovascular control by novel methods of heart rate dynamics. Philos Trans A Math Physica Eng Sci 2009; 367: 1223-1238

23 Pikkujämsä SM, Mäkikallio TH, Sourander LB, Räihä IJ, Puukka P, Skyttä J et al. Cardiac interbeat interval dynamics from childhood to senescence: comparison of conventional and new measures based on fractals and chaos theory. Circulation 1999; 100: 393-399.

24 Mäkikallio TH, Ristimäe T, Airaksinen KEJ, Peng CK, Goldberger AL, Huikuri HV. Heart rate dynamics in patients with stable angina pectoris and utility of fractal and complexity measures. Am J Cardiol 1998; 81: 27-31.

25 Tulppo MP, Hughson RL, Mäkikallio TH, Airaksinen KE, Seppänen T, Huikuri HV. Effects of exercise and passive head-up tilt on fractal and complexity properties of heart rate dynamics. Am J Physiol Heart Circ Physiol 2001; 280: H1081-H1087.

26 Kanters JK, Højgaard MV, Agner E, Holstein-Rathlou NH. Short- and long-term variations in non-linear dynamics of heart rate variability. Cardiovasc Res 1996; 31: 400-409.

27 Ziegler D, Piolot R, Strassburger K, Lambeck H, Dannehl K. Normal ranges and reproducibility of statistical, geometric, frequency domain, and non-linear measures of 24-hour heart rate variability. Horm Metab Res 1999; 31: 672-679.

28 Maestri R, Pinna GD, Porta A, Balocchi R, Sassi R, Signorini MG et al. Assessing nonlinear properties of heart rate variability from short-term recordings: are these measurements reliable? Physiol Meas 2007; 28: 1067-1077.

29 La Fountaine MF, Wecht JM, Spungen AM, Bauman WA. Intra-inter visit reproducibility of short-term linear and nonlinear measurement of heart rate variability in tetraplegia and neurologically intact controls. Physiol Meas 2010; 31: 363-374.

30 Tan CO, Cohen MA, Eckberg DL, Taylor JA. Fractal properties of human heart period variability: physiological and methodological implications. J Physiol 2009; 587: 3929-3941.

31 Tulppo MP, Mäkikallio TH, Takala TE, Seppänen T, Huikuri HV. Quantitative beat-tobeat analysis of heart rate dynamics during exercise. Am J Physiol 1996; 271: H244-H252.

32 Perkiömäki JS, Zareba W, Badilini F, Moss AJ. Influence of atropine on fractal and complexity measures of heart rate variability. Ann Noninvasive Electrocardiol 2002; 7: 326-331.

33 Palazzolo JA, Estafanous FG, Murray PA. Entropy measures of heart rate variation in conscious dogs. Am J Physiol 1998; 274: H1099-H1105.

34 Penttilä J, Helminen A, Jartti T, Kuusela T, Huikuri HV, Tulppo MP et al. Effect of cardiac vagal outflow on complexity and fractal correlation properties of heart rate dynamics. Auton Autacoid Pharmacol 2003; 23: 173-179.

35 Millar PJ, Cotie LM, St Amand T, McCartney N, Ditor DS. Effects of autonomic blockade on nonlinear heart rate dynamics. Clin Auton Res 2010; 20: 241-247.

36 Platisa MM, Mazic S, Nestorovic Z, Gal V. Complexity of heartbeat interval series in young healthy trained and untrained men. Physiol Meas 2008; 29: 439-450.

37 Tulppo MP, Mäkikallio TH, Seppänen T, Shoemaker K, Tutungi E, Hughson RL et al. Effects of pharmacological adrenergic and vagal modulation on fractal heart rate dynamics. Clin Physiol 2001; 21: 515-523.

38 Tulppo MP, Kiviniemi AM, Hautala AJ, Kallio M, Seppänen T, Mäkikallio TH et al. Physiological background of the loss of fractal heart rate dynamics. Circulation 2005; 112: 314-319.
39 Berger RD, Kasper EK, Baughman KL, Marban R, Calkins H, Tomaselli GF et al.. interval variability. Novel evidence for repolarization lability in ischemic and nonischemic dilated cardiomyopathy. Circulation 1997; 96: 1557-1565.

40 Atiga WL, Calkins H, Lawrence J, Tomaselli GF, Smith JS, Berger RD. Beat-to-beat repolarization lability identifies patients at risk for sudden cardiac death. J Cardiovasc Electrophysiol 1998; 9: 899-908.

41 Ahnve S, Vallin $\mathrm{H}$. Influence of heart rate and inhibition of autonomic tone on the QT interval. Circulation 1982; 65: 435-439.

42 Yeragani VK, Pohl R, Jampala VC, Balon R, Kay J, Igel G. Effect of posture and isoproterenol on beat-to-beat heart rate and qt variability. Neuropsychology 2000; 41: 113-123.

43 Sharif $\mathrm{H}$, Cotie LM, La Fountaine MF, Ditor DS. The influence of cardiac autonomic activity on the QT-variability index in able-bodied and incomplete spinal cord injured individuals. Auton Neurosci 2015; 190: 46-52

44 Baumert M, Schlaich PM, Nalivaiko E, Lambert E, Sari Cl, Kaye DM et al. Relation between QT interval variability and cardiac sympathetic activity in hypertension. Am J Physiol Heart Circ Physiol 2011; 300: H1412-H1417.

45 Khandoker AH, Imam MA, Couderc JP, Palaniswami M, Jelinek H. QT variability index changes with severity of cardiovascular autonomic neuropathy. IEEE Trans Inf Technol Biomed 2012; 16: 900-906.

46 Piccirillo G, Cacciafesta M, Lionetti M, Nocco M, Di Giuseppe V, Moise A et al. Influenve of age, the autonomic nervouse system and anxiety on QT-interval variability. Clin Sci 2001; 101: 429-439.

47 Piccirillo G, Magri D, Ogawa M, Song J, Chong VJ, Han S et al. Autonomic nervous system activity measured directly and qt interval variability in normal and pacinginduced tachycardia heart failure dogs. J Am Coll Cardiol 2009; 54: 840-850.

48 Kleiger RE, Miller PJ, Bigger JT, Moss AJ. Decreased heart rate variability and its association with increased mortality after acture myocardial infarction. Am J Cardiol 1987; 59: 256-262.

49 La Rovere MT, Bigger JT, Marcus FI, Mortara A, Schwartz PJ. Baroreflex sensitivity and heart-rate variability in prediction of total cardiac mortality after myocardial infarction. The Lancet 1998; 351: 478-484.

50 Algra A, Tijssen JGP, Roelandt JRTC, Pool J, Lubsen J. Heart rate variability from 24-hour electrocardiography and the 2-year risk for sudden death. Circulation 1993; 88: $180-185$.

51 Langewitz W, Rüddel H, Schächinger $\mathrm{H}$. Reduced parasympathetic cardiac control in patients with hypertension at rest and under mental stress. Am Heart J 1994; 127: 122-128.

52 Casolo G, Balli E, Taddei T, Amuhasi J, Gori C. Decreased spontaneous heart rate variability in congestive heart failure. Am J Cardiol 1989; 64: 1162-1167.

53 Pagani M, Malfatto G, Pierini S, Casati R, Masu AM, Poli M et al. Spectral analysis of heart rate variability in the assessment of autonomic diabetic neuropathy. J Auton Nerv Sys 1988; 23: 143-153.

54 Lombardi F, Sandrone G, Pernpruner S, Sala R, Garimoldi M. Cerutti. Heart rate variability as an index of sympatho-vagal interaction after acute myocardial infarction. Am J Cardiol 1987; 60: 1239-1245.

55 Lombardi F. Sandrone G, Mortara A, La Vovere MT, Columbo E, Guzzetti S et al. Circadian variation of spectral indices of heart rate variability after myocardial infarction. Am Heart J 1992; 123: 1521-1529.

56 Lucreziotti S, Gavazzi A, Scelsi L, Inserra C, Klersy C, Campana C et al. Five-minute recording of heart rate variability in severe chronic heart failure: correlates with right ventricular function and prognostic implications. Am Heart J 2000; 139: 1088-1095.

57 Galinier M, Pathak A, Fourcade J, Androdias C, Curnier D, Varnous S et al. Depressed low frequency power of heart rate variability as an independent predictor of sudden death in chronic heart failure. Eur Heart J 2000; 21: 475-482.

58 Bigger JT, Steinman RC, Rolnitzky LM, Fleiss JL, Albrecht P, Cohen RJ. Power law behavior of RR-interval variability in healthy middle-aged persons, patients with recent acute myocardial infarction, and patients with heart transplants. Circulation 1996; 93 : 2142-2151.

59 Singer $\mathrm{DH}$, Ori Z. Changes in heart rate variability associated with sudden cardiac death. In: Heart Rate Variability. Armonk Futura 1995, 429-448.

60 Mäkikallio TH, Høiber S, Køber L, Torp-Pedersen C, Peng CK, Goldberger Al et al. Fractal analysis of heart rate dynamics as a predictor of mortality in patients with depressed left ventricular function after acute myocardial infarction. Am J Cardiol 1999; 83: 836-839.

61 Huikuri HV, Mäkikallio TH, Peng CK, Goldberger AL, Hintze U, Møller M. Fractal correlation properties of R-R interval dynamics and mortality in patients with depressed left ventricular function after an acute myocardial infarction. Circulation 2000; 101: 47-53.

62 Stein PK, Domitrovich PP, Huikuri HV, Kleiger RE. Traditional and nonlinear heart rate variability are each independently associated with mortality after myocardial infarction. J Cardiovasc Electrophysiol 2005; 16: 13-20.

63 Mäkikallio TH, Seppänen T, Airaksinen KE, Koistinen J, Tulppo MP, Peng CK et al. Dynamic analysis of heart rate may predict subsequent ventricular tachycardia after myocardial infarction. Am J Cardiol 1997; 80: 779-783.

64 Mäkikallio TH, Seppänen T, Niemelä M, Airaksinen KE, Tulppo M, Huikuri HV. Abnormalities in beat to beat complexity of heart rate dynamics in patients with a previous myocardial infarction. J Am Coll Cardiol 1996; 28: 1005-1011.

65 Perkiömäki JS, Jokinen V, Tapanainen J, Airaksinen KE, Huikuri HV. Autonomic markers as predictors of nonfatal acute coronary events after myocardial infarction. Ann Noninvasive Electrocardiol 2008; 13: 120-129. 
66 Perkiömäki JS, Hämekoski S, Junttila MJ, Jokinen V, Tapanainen J, Huikuri HV. Predictors of long-term risk for heart failure hospitalization after acute myocardial infarction. Ann Noninvasive Electrocardiol 2010; 15: 250-258.

67 Norris PR, Anderson SM, Jenkins JM, Williams AE, Morris JA Jr. Heart rate multiscale entropy at three hours predicts hospital mortality in 3,154 trauma patients. Shock 2008a; 30: 17-22.

68 Norris PR, Stein PK, Morris JA Jr. Reduced heart rate multiscale entropy predicts death in critical illness: a study of physiologic complexity in 285 trauma patients. J Crit Care 2008b; 23: 399-405.

69 Huikuri HV, Mäkikallio TH, Airaksinen KE, Seppänen T, Puukka P, Räihä IJ et al. Power-law relationship of heart rate variability as a predictor of mortality in the elderly. Circulation 1998; 97: 2031-2036.

70 Piccirillo G, Magnanti M, Matera S, Carlo SD, Laurentis TD, Torrini A et al. Age and QT variability index during free breathing, controlled breathing and tilt in patients with chronic heart failure and healthy control subjects. Trans/ Res 2006; 148: 72-78.

71 Yeragani VK, Pohl R, Jampala VC, Balon R, Ramesh C, Srinivasan K. Increased QT variability in patients with panic disorder and depression. Psychiatry Res 2000; 93 225-235.

72 Piccirillo G, Magri D, Matera S, Magnanti M, Torrini A, Pasquazzi E et al. 2007QT variability strongly predicts sudden cardiac death in asymptomatic subjects with mild or moderate left ventricular systolic dysfunction: a prospective study. Eur Heart J 2007; 28: $1344-1350$.

73 Tereshchenko LG, Cygankiewicz I, McNitt S, Vasquez R, Bayes Genis A, Han L et al. Predictive value of beat-to-beat qt variability index across the continuum of left ventricular dysfunction: competing risks of noncardiac or cardiovascular, death and sudden or non-sudden cardiac death. Circ Arrhythm Electrophysiol 2012; 5: 719-727.

74 Ditor S, Kamath MV, MacDonald MJ, Bugaresti J, McCartney N, Hicks AL. Reproducibility of heart rate variability and blood pressure variability in individuals with spinal cord injury. Clin Auton Res 2005; 6: 387-393.

75 Inoue K, Miyake S, Kumashiro M, Ogata H, Ueta T, Akatsu T. Power spectral analysis of blood pressure variability in traumatic quadriplegic humans. Am J Physiol 1990; 260: H842-H847.

76 Koh J, Brown TE, Beightol LA, Ha CY, Eckberg DL. Human autonomic rhythms: vagal cardiac mechanisms in tetraplegic subjects. J Physiol 1994; 474: 483-495.

77 Guzzetti S, Cogliati C, Broggi C, Carozzi C, Caldiroli D, Lombardi F et al. Influences of neural mechanisms on heart period and arterial pressure variabilities in quadriplegic patients. Am J Physiol 1994; 35: H1112-H1120.

78 Inoue K, Ogata H, Hayano J. Assessment of autonomic function in traumatic quadriplegic and paraplegic patients by spectral analysis of heart rate variability. J Auton Nerv Sys 1995; 54: 225-234.

79 Claydon VE, Elliott SL, Sheel AW, Krassioukov A. Cardiovascular responses to vibrostimulation for sperm retrieval in men with spinal cord injury. J Spinal Cord Med 2006; 29: 207-216.

80 Grimm DR, DeMeersman RE, Almenoff PL, Spungen AM, Bauman WA. Sympathovaga balance of the heart in subjects with spinal cord injury. Am J Physiol 1997; 272: H835-H842.

81 Wang YH, Huang TS, Lin JL, Hwang JJ, Chan HL, Lai JS et al. Decreased autonomic nervous system activity as assessed by heart rate variability in patients with chronic tetraplegia. Arch Phys Med Rehabil 2000; 81: 1181-1184.
82 Wecht JP, Weir JP, Bauman WA. Blunted heart rate response to vagal withdrawal in persons with tetraplegia. Clin Auton Res 2006; 16: 378-383.

83 Wecht JM, Weir JP, DeMeersman RE, Schilero GJ, Handrakis JP, LaFountaine MF et al. Cold face test in persons with spinal cord injury: age versus inactivity. Clin Auton Res 2009; 19: 221-229.

84 Kinoshita T, Nagata S, Baba R, Kohmoto T, Iwagaki S. Cold-water face immersion per se elicits cardiac parasympathetic activity. Circ J 2006; 70: 773-776.

85 Uijtdehaage SH, Thayer JF. Accentuated antagonism in the control of human heart rate. Clin Auton Res 2000; 10: 107-110.

86 Fagius J, Sundlof G. The diving response in man: effects on sympathetic activity in muscle and skin nerve fascicles. J Physiol 1986; 377: 429-443.

87 Ditor DS, Kamath MV, MacDonald MJ, Bugaresti J, Adams M, McCartney N et al. The effects of body weight supported treadmill training on heart rate variability and blood pressure variability in individuals with spinal cord injury. J Appl Physiol 2005; 98: 1519-1525.

88 Zamunér AR, Silva E, Teodori RM, Catai AM, Moreno MA. Autonomic modulation of heart rate in paraplegic wheelchair basketball players: linear and nonlinear analysis. J Sports Sci 2013; 31: 396-404.

89 Wecht JM, Marsico R, Weir JP, Spungen AM, Bauman WA, De Meersman RE. Autonomic recovery from peak arm exercise in fitand unfit individuals with paraplegia. Med SCI Sports Exerc 2006; 38: 1223-1228.

90 Grimm DR, DeMeersman RE, Garofano RP, Spungen AM, Bauman WA. Effect of provocative maneuvers on heart rate variability in subjects with quadriplegia. Am J Physiol 1995; 268: H2239-H2245.

91 Ditor DS, Allison D, Kamath MV. Effects of spinal cord injury on heart rate variability and blood pressure variabilityKamath. In: Kamath IN, Watanabe MV, Upton MA (eds) Heart Rate Variability (HRV) Signal Analysis. Clinical Application. Taylor \& Francis Group: NY, USA, 2013; pp 371-392.

92 Cotie LM, St Amand T, McMilan R, Picton P, Ditor DS. Effects of autonomic blockade on heart rate variability after spinal cord injury: A case series. Crit Rev Phys Rehabil Med 2010; 22: 1-12.

93 Merati G, Di Rienzo M, Parati G, Veicsteinas A, Castiglioni P. Assessment of the autonomic control of heart rate variability in healthy and spinal-cord injured subjects: contribution of different complexity-based estimators. IEEE Trans Biomed Eng 2006; 53: 43-52.

94 Agiovlasitis S, Heffernan KS, Jae SY, Ranadive SM, LeeM, Mojtahedi MC et al. Effects of paraplegia on cardiac autonomic regulation during static exercise. Am J Phys Med Rehabil 2010; 89: 817-823.

95 Millar PJ, Rakobowchuk M, Adams MM, Hicks AL, McCartney N, MacDonald MJ. Effects of short-term training on heart rate dynamics in individuals with spinal cord injury. Auton Neurosci 2009; 150: 116-121.

$96 \mathrm{La}$ Fountaine MF, Wecht JM, Rosado-Rivera D, Cirnigliaro CM, Spungen AM, Bauman WA. The QT variability index and cardiac autonomic modulation: perspectives from apparently healthy men with spinal cord injury. Cardiology 2010; 117: 253-259.

97 Ravensbergen HJ, Walsh ML, Krassioukov AV, Claydon VE. Electrocardiogram-based predictors for arrhythmia after spinal cord injury. Clin Auton Res 2012; 22: 265-273. 